\title{
Epidemiological Data Concerning Canine Lymphoma over a Ten-Year Period (2005-2014), in Cluj-Napoca, Romania
}

\author{
Roxana CORA, Adrian Florin GAL, Flaviu TĂBĂRAN, Marian TAULESCU, Andras NAGY, \\ Raluca VIDRIGHINESCU, Cornel CǍTOI \\ ${ }^{1}$ Faculty of Veterinary Medicine, University of Agricultural Sciences and Veterinary Medicine, 3-5 \\ Mănăştur Street, 3400 Cluj-Napoca, Romania \\ * Corresponding author: roxanacora88@yahoo.com
}

Bulletin UASVM Veterinary Medicine 73(1) / 2016,

Print ISSN 1843-5270; Electronic ISSN 1843-5378

DOI:10.15835/buasvmcn-vm: 11673

\begin{abstract}
Lymphoma is one of the main neoplasms that affects dogs, representing $80-90 \%$ of all hematopoietic tumors and $8-9 \%$ of all tumors. In the current paper we assessed the incidence of canine lymphomas that were diagnosed in the Pathology Department (Faculty of Veterinary Medicine, Cluj-Napoca, Romania) over a ten-year period (2005-2014).The epidemiological data were collected from the records of the Pathology Department (Faculty of Veterinary Medicine, Cluj-Napoca, Romania) in the last decade. The investigation included dogs diagnosed with lymphoma, following necropsy analysis or assessment of biopsies or cytological samples collected by fine needle aspiration from lymph nodes. All collected specimens were analyzed for histopathological diagnosis. We analyzed the distribution of canine lymphoma in relation to age, breed and sex, as well as the proportion of each anatomical form of lymphoma. The highest prevalence of lymphoma was observed in dogs aged 6 to 9, in Mongrels, Rottweiler and German shepherd dogs, with a very small difference between males and females. $79.8 \%$ of the dogs in this study were diagnosed with multicentric lymphoma, 5.76\% with the gastrointestinal form, 5.76\% with the cutaneous form, $4.8 \%$ were extranodal lymphomas and 3.84\% were mediastinal ones. The results we obtained are agree with the statistics cited in the research literature. Considering that canine lymphoma is a common tumor in individuals of various ages, sexes and breeds, further epidemiological reports may aid in the establishment of the main risk factors for this entity.
\end{abstract}

Keywords: dog, epidemiology, lymphoma

\section{INTRODUCTION}

Lymphoma is a malignant disorder derived from clonal proliferation of lymphoid precursor cells (Ettinger, 2003; Chung et al., 2014). Lymphoma is a common neoplastic disease in dogs (Ueno et al., 2014), which can represent up to $24 \%$ of all tumors (Dank et al., 2011) and $85 \%$ of diagnosed hematological malignancies in this species (O'Connor and Wilson-Robles, 2014). Multicentric lymphoma is the most frequent anatomical form, accounting for nearly $80 \%$ of all canine lymphomas (Vail and Young, 2007; Wiggans et al., 2014).
Digestive lymphoma represents about $7 \%$ of cases, while the mediastinal (thymic) form is found in nearly 3\% of canine lymphomas (Vail, 2010).

Cutaneous lymphoma (6\% of cases) can be primary or secondary (i.e., often associated with other forms of lymphoma). Primary cutaneous lymphoma has two manifestations, in both cases frequently deriving from $\mathrm{T}$ lymphocytes. Epitheliotropic lymphoma (mycosis fungoides) is characterized by the involvement of epidermis, while the second form (non-epitheliotropic lymphoma) is more aggressive (Morris and Dobson, 2001). 
Extranodal lymphoma is a rare form that can affect a number of tissues in the body. The most common locations of the extranodal lymphoma are the ocular and neural ones (Neuwald et al., 2014).

Other atypical forms of lymphoma such as hepatosplenic lymphoma that was rarely observed in dogs (Vail et al., 2013) were described in the reseach literature. Another unusual form is the intravascular (angiotropic) lymphoma, which is characterized by the proliferation of lymphocytes that have suffered a neoplastic transformation within the vascular lumen and in the wall of blood vessels, in the absence of an extravascular primary tumor or leukemia. (Bush et al., 2003; Ridge and Swinney, 2004; Vail et al., 2013).

Phenoxyacetic pesticides (particularly 2-, 4-dichlorophenoxyacetic) are incriminated in the etiology of canine lymphoma. A higher prevalence of malignant lymphoma in dogs whose owners utilized pesticides (Hayes et al., 1991) was noticed in a study conducted on patients in a veterinary clinic.

In another study conducted in Europe, the authors suggested a couple of variables in the etiology of canine lymphoma: the use of chemical solvents and the accommodation in industrialized (heavily polluted) areas. Dogs exposed to these circumstances had a higher risk to develop malignant lymphoma (Gavazza et al., 2001).

The annual incidence of malignant lymphoma varies from 24 to 114 cases per 100.000 dogs (Dubson et al., 2002; Dorn et al., 1967; Priest et al., 2011). It is known that lymphoma can occur in dogs of all ages, but frequently medium aged subjects are affected (Teske, 1994). The highest frequency of lymphoma is found in the age group between 5.5 to 9 years (Baba and Cătoi, 2007). Other authors noticed a progressive increase of the incidence of lymphoma with a maximum at the age of 11, after which the incidence decreases (Modiano et al., 2005).

A retrospective study conducted in Poland for the duration of 3 years, on 63 cases with lymphoma, showed that males (62\%) were more frequently affected than females (38\%) (Jagielski et al., 2002).

The prevalence of certain phenotypes of lymphoma differs according to the breed. Some dog breeds have a distinct, reproducible and significant predisposition to malignant lymphoma, suggesting that the genetic risk and at the same time, the protective factors for lymphoma are associated with some specific breed features. Dog breeds with the highest prevalence of malignant lymphoma are Golden Retriever, Labrador Retriever, Cocker Spaniel, Rottweiler, Boxer, German Shepherd, Doberman Pinscher (Modiano et al., 2005).

In the current paper, we assessed the incidence of canine lymphoma that was diagnosed in the Department of Pathology (Faculty of Veterinary Medicine, Cluj-Napoca, Romania) for a period of ten years (2005-2014).

\section{MATERIALS AND METHODS}

The epidemiological study was conducted ver a period of 10 years (2005-2014), using the records of the Pathology Department (Faculty of Veterinary Medicine, Cluj-Napoca, Romania). The investigation included dogs diagnosed with lymphoma, following the analysis of corpses,

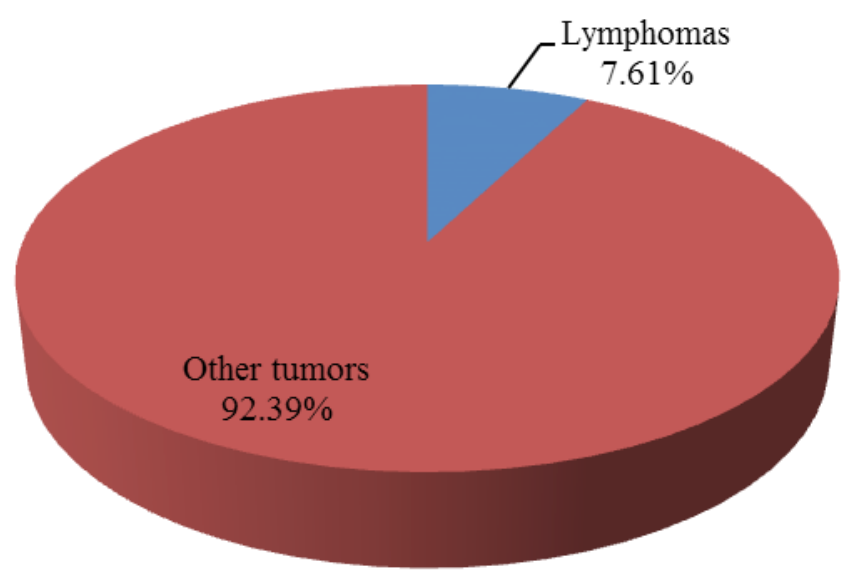

Fig.1. The proportion of lymphoma cases from the total number of dogs with tumoral lesions. 
biopsies or cytological samples. In all cases, the diagnosis of lymphoma was established by histopathological examination (biopsies and corpses) and/or by cytological examination (samples collected by fine needle aspiration technique from lymph nodes). Cases included in the report originate from Cluj County and from other neighboring counties. The following variables were analyzed: sex, age, breed, sample type and location of the lymphoma.

\section{RESULTS AND DISCUSSION}

The results obtained following the processing the data from the records of the Pathology Department, are presented below. A total of 4014 dogs were included in this investigation, out of which 1365 displayed various neoplastic lesions; a number of 104 cases (out of 1365 subjects with tumoral lesions) were diagnosed with malignant lymphoma. The diagnosis was established after performing the necropsy and histopathological examination of canine corpses (57 cases), or by assessing biopsies (11 cases) and cytological specimens acquired by fine needle aspiration method (36 cases).

In the assessed decade, malignant lymphoma represented $7.61 \%$ from the total tumor pathology. The result, graphically represented in Figure 1, is somehow similar to some other records mentioned in the literature, which indicates a percentage of 8-9\% for the suggested tumor (Baba and Cătoi, 2007). From the total number of dogs evaluated in the above-mentioned decade (i.e., 4014 dogs), the cases with malignant lymphoma represented about $2.59 \%$.

Calculating the percentage of all lymphomas each year, we the results vary from $3.75 \%$ in 2006 to $15.12 \%$ in 2014. From 2010, there was

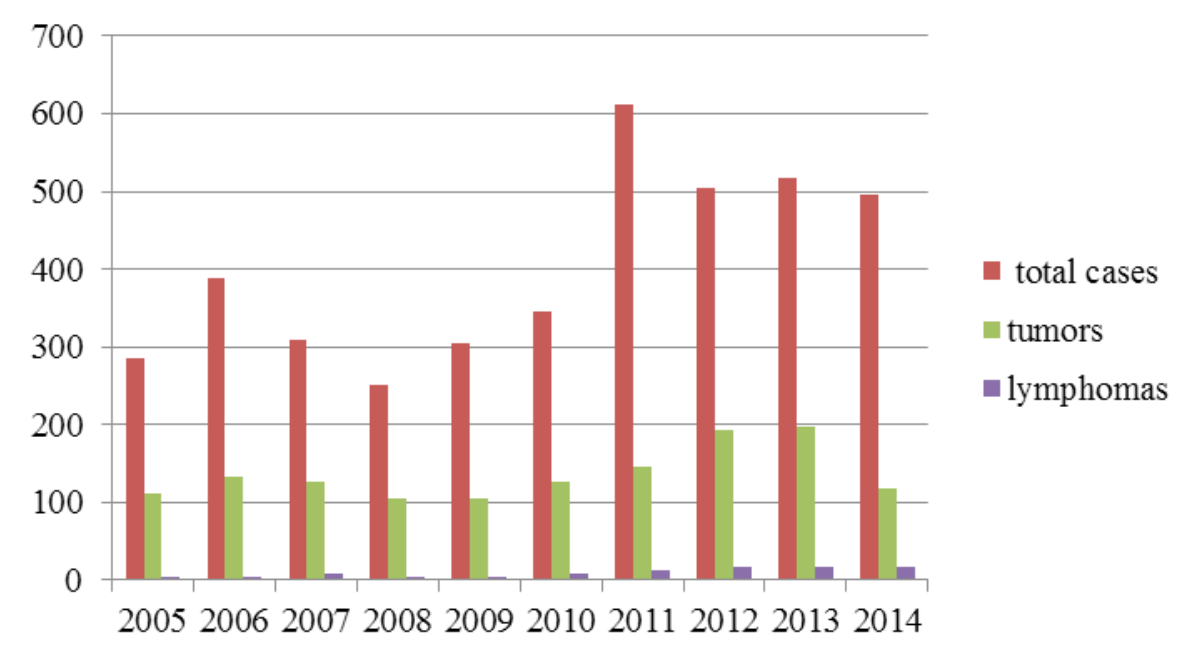

Fig. 2. Distribution of tumors and lymphomas in the assessed decade.

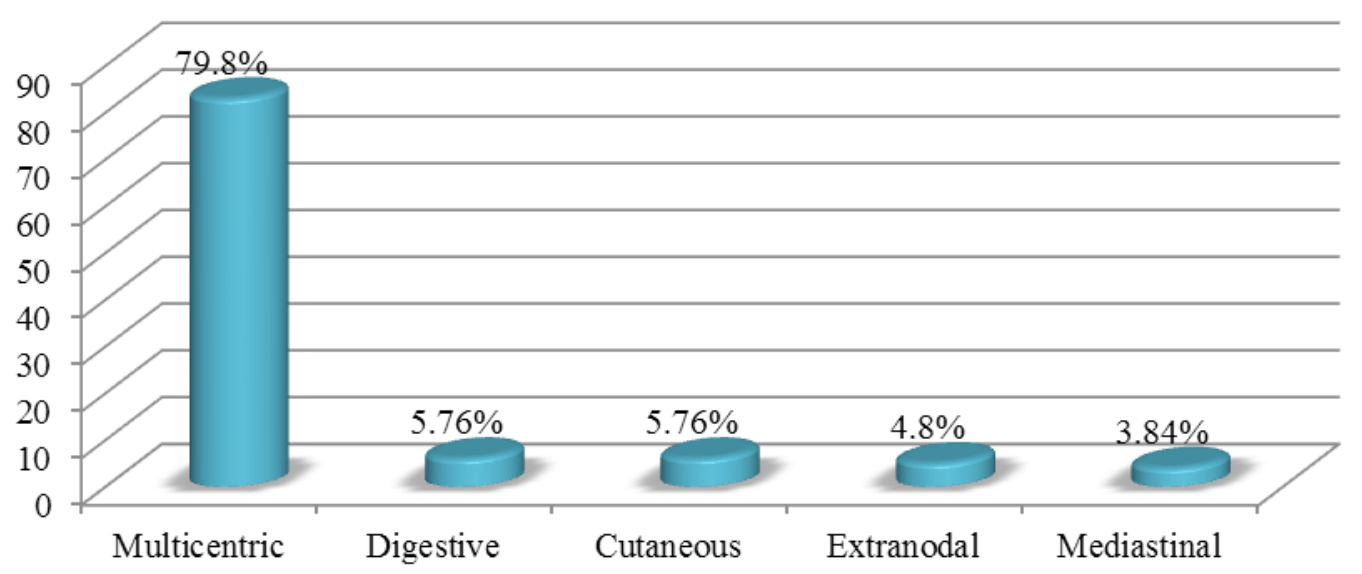

Fig. 3. Distribution of canine lymphoma depending on the body region. 
a progressive increase in the number of canine lymphoma cases brought to the Pathology Department. Figure 2 shows the number of lymphoma cases as compared to the number of cases with tumor pathology, and related to all dogs examined in each year.

From the total of lymphoma cases, 79.8\% were diagnosed as multicentric lymphoma, about $5.76 \%$ with digestive and cutaneous lymphoma, $4.8 \%$ with extranodal lymphoma, and $3.84 \%$ of cases with mediastinal lymphoma. The distribution of cases according to the anatomical site is graphically represented in the Figure 3 . The results are similar to some other research reports, showing that about $80 \%$ of cases with canine lymphoma are represented by the multicentric form, followed by the digestive lymphoma (7\%), cutaneous form (6\%), mediastinal lymphoma (3\%); the rest of cases were represented by atypical forms (Vail, 2010).

From 104 cases, in 10 subjects the gender was not mentioned. Accordingly, out of the remaining

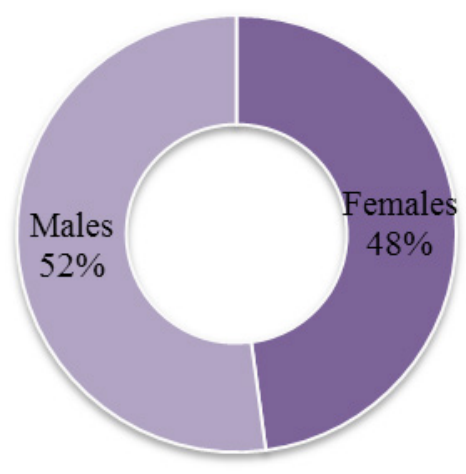

Fig. 4. The distribution of malignant lymphoma according to the gender of investigated dogs.

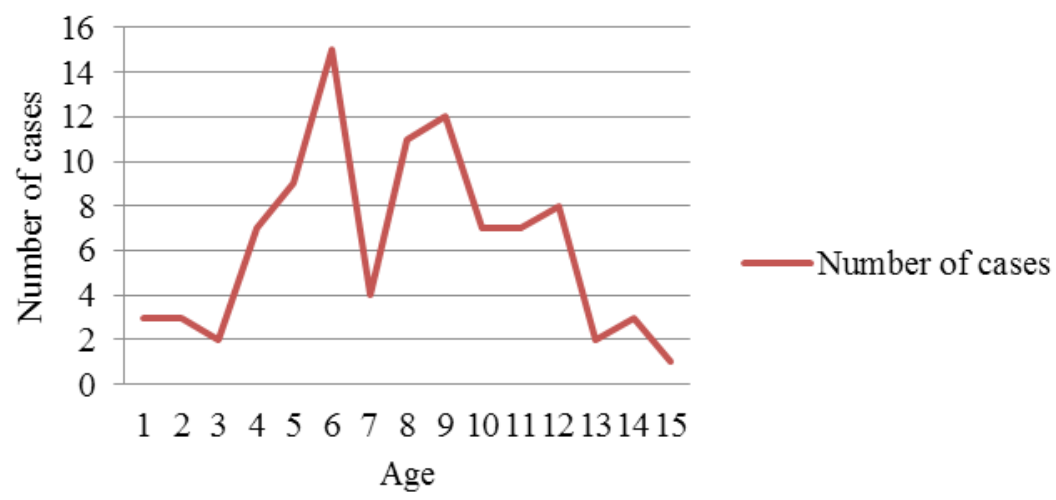

Fig. 5. Distribution of cases with lymphoma according to the age of dogs.

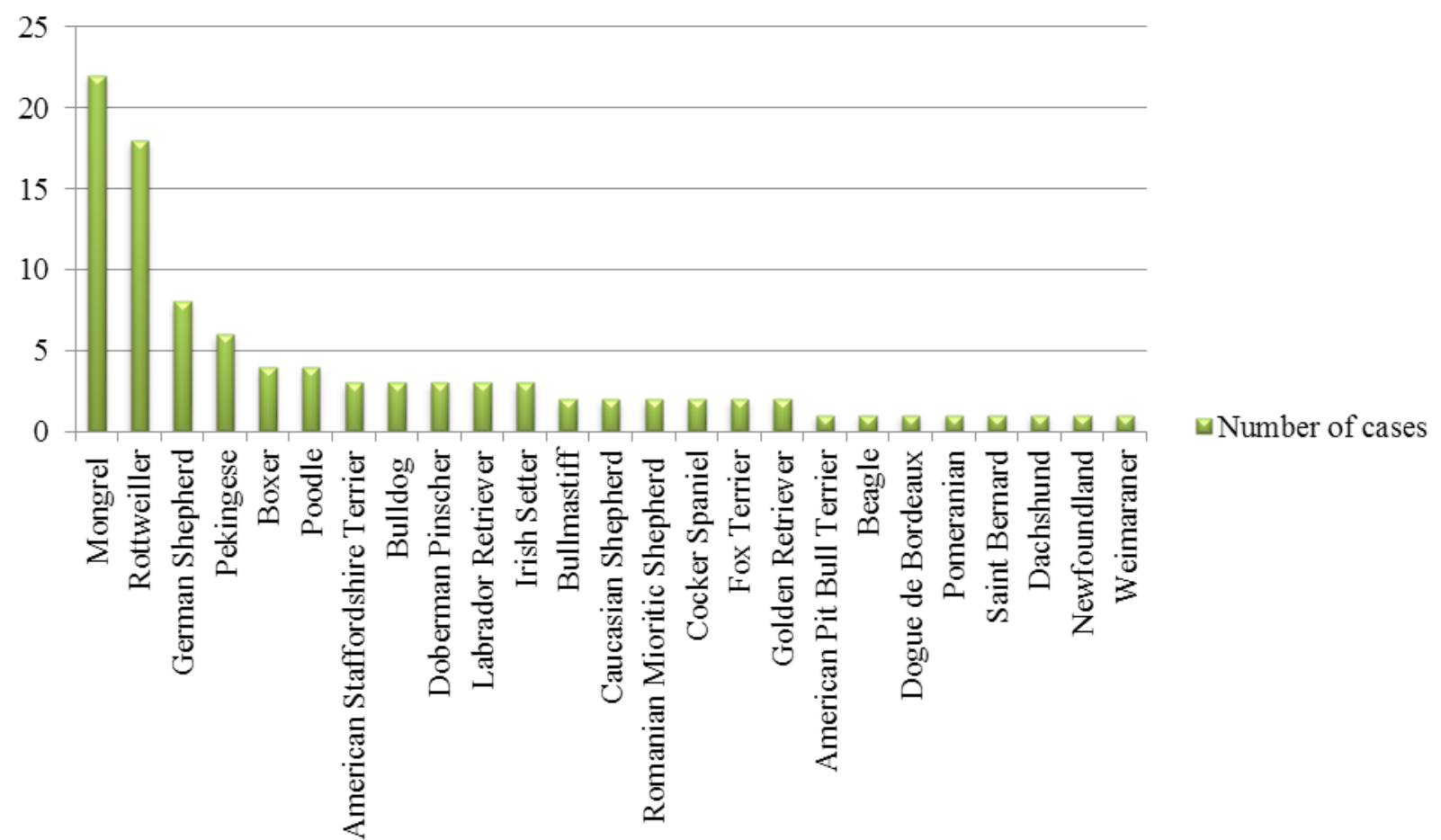

Fig. 6. Distribution of cases with lymphoma according to the breed. 
cases (i.e., 94 canine subjects), lymphomas occurred in males in a proportion of $52 \%$ and in females in $48 \%$ of cases (graphically represented in Figure 4). Out findings are similar with a number of other findings, which suggest that males have a slightly higher risk to develop lymphoma. The difference between the incidence of lymphoma in males and females is significantly lower in the case of neutered females. This could be due to hormonal changes that occur after ovariectomy/ ovariohysterectomy, suggesting that the estrogen may represent a protective factor (Villamil et al., 2009).

Most cases of lymphoma (15 cases) were detected in 6 year-old dogs, followed by 9 yearold individuals (12 cases) and 8 year-old dogs (11 cases), respectively. In a number of 10 subjects, the age was not specified. The average age at which the lymphoma occurred was 7.74 years. As observed in Figure 5, there is a gradual increase of dog cases with lymphoma starting from the age of 3 (years), with a maximum of cases around the age of 6 (years); a regular decrease in the number of cases was observed from the age of 9 (years). According to some other reports, it is estimated that the highest frequency of lymphoma occurs in the age group between 5.5 and 8 year-old dogs (Baba and Cătoi, 2007).

After processing the data from our records, we noticed that the highest number of lymphoma cases were diagnosed in Mongrels (22 cases), followed by Rottweiler (18 cases) and German shepherd (8 cases). It is known, as suggested by others, that some canine breeds such as: Rottweiler, German shepherd and Boxer have a predisposition for developing lymphoma (Modiano et al., 2005). As suggested in the Figure 6, in our report Boxer dogs were not included among the most affected breeds. In a number of 7 cases, the breed was not specified.

\section{CONCLUSION}

During the period 2005-2014, malignant lymphoma represented $7.61 \%$ of all tumoral lesions in dogs, the suggested neoplasia being one of the most important in this species. Individuals between 6 to 9 years old were the main affected age group. The Mongrels, Rottweiler and German shepherd dogs were more commonly diagnosed with lymphoma, with an insignificant difference between males and females. The predominant form was the multicentric lymphoma (about 80\%), followed by the digestive, cutaneous, mediastinal and extranodal forms.

\section{REFERENCES}

1. Baba AI, Cătoi C (2007). Comparative oncology. The Romanian Academy Publishing House, 587-619.

2. Bush WW, Throop JL, McManus PM, Kapatkin AS, Vite CH, Van Winkle TJ (2003). Intravascular lymphoma involving the central and peripheral nervous systems in a dog. J Am Anim Hosp Assoc 39:90-96

3. Chung TH, Lamm C, Choi VC, Lee JW, Yu D, Choi US (2014). A rare case of hepatic t- cell rich b-cell lymphoma (tcrbcl) in a juvenile dog. J Vet Med Sci 76(10):1393-1397.

4. Dank G, Rassnick KM, Kristal O, Rodriguez CO, Clifford CA,Ward R, Mallett CL, Gieger T, Segev G (2011). Clinical characteristics, treatment, and outcome of dogs with presumed primary hepatic lymphoma: 18 cases (19922008). J Am Vet Med Assoc 239(7):966-971.

5. Dorn CR, Taylor DO, Hibbard HH (1967). Epizootiologic characteristics of canine and feline leukemia and lymphoma. Am J Vet Res 28:993-1001.

6. Dubson JM, Samuel S, Milstein H, Rogers K, Wood JL (2002). Canine neoplasia in the UK: estimates of incidence rates from a population of insured dogs. J Small Anim Pract 43:240-246.

7. Ettinger SN (2003). Principles of treatment for canine lymphoma. Clin Tech Small Anim Pract 18:92-97.

8. Gavazza A, Presciuttini S, Barale R (2001). Association between canine malignant lymphoma, living in industrial areas, and use of chemicals by dog owners. J Vet Intern Med 15:190-195.

9. Hayes HM, Tarone RE, Cantor KP (1991). Case-control study of canine malignant lymphoma: Positive association with dog owner's use of 2, 4-dichlorophenoxyacetic acid herbicides. J Natl Cancer Inst 83:1226-1231.

10. Jagielski D, Lechowski R, Hoffmann-Jagielska M, Winiarczyk $S$ (2002). A retrospective study of the incidence and prognostic factors of multicentric lymphoma in dogs (1998-2000). J Vet Med A 49:419-424.

11. Modiano JF, Breen M, Burnett RC, Parker HG, Inusah S, Thomas R, Avery PR, Lindblad-Toh K, Ostrander EA, Cutter GC, Avery AC (2005). Distinct B-Cell and T-Cell Lymphoproliferative Disease Prevalence among Dog Breeds Indicates Heritable Risk. Cancer Res 65(13):56545661.

12. Morris J, Dobson J (2001). Small Animal Oncology. Blackwell Science, 228-238.

13. Neuwald EB, Teixeira LV, Conrado FO, da Silva MOD, Hlavac NRC, González FHD (2014). Epidemiological, clinical and immunohistochemical aspects of canine lymphoma in the region of Porto Alegre, Brazil. Pesq Vet Bras 34(4):349354.

14. O'Connor CM, Wilson-Robles H (2014). Developing T Cell Cancer Immunotherapy in the Dog with Lymphoma. ILAR J 55(1):169-181. 
15. Priest H, McDonough S, Erb H, Daddona J, Stokol T (2011). Transferrin receptor expression in canine lymphoma. Vet Pathol 48(2):466-474.

16. Ridge L, Swinney G (2004). Angiotrophic intravascular lymphosarcoma presenting as bi- cavity effusion in a dog. Aust Vet J 82:616-618.

17. Teske E (1994). Canine malignant lymphoma: a review and comparison with human non- Hodgkin's lymphoma. Vet Quarterly 16(4):209-219.

18. Ueno H, Miyoshi K, Fukui S, Kondo Y, Matsuda K, Uchide T (2014). Extranodal Lymphoma with Peripheral Nervous System Involvement in a Dog. J Vet Med Sci 76(5):723727.

19. Vail DM (2010). BSAVA Manual of canine and feline oncology. British Small Animal Veterinary Association, Quedgeley, Gloucester, 285-303.
20. Vail DM, Pinkerton ME, Young KM (2013). Withrow and MacEwen's Small Animal Clinical Oncology. Elsevier/Saunders, St. Louis, 608-631.

21. Vail DM, Young KM (2007). Hematopoietic tumors. In: Withrow SJ, Vail DM (eds.). Withrow and MacEwen's small animal clinical oncology, Saunders Elsevier, St Louis 699- 784.

22. Villamil JA, Henry CJ, Hahn AW, Bryan JN, Tyler JW, Caldwell CW (2009). Hormonal and Sex Impact on the Epidemiology of Canine Lymphoma. J Cancer Epidemiol 2009:591753. doi:10.1155/2009/591753

23. Wiggans TK, Skorupski KA, Reilly CM, Frazier SA, Dubielzig RR, Maggs DJ (2014). Presumed solitary intraocular or conjunctival lymphoma in dogs and cats: 9 cases (19852013). J Am Vet Med Assoc 244(4):460-470. 